\title{
Standing Mesochannels: Mesoporous PdCu Films with Vertically Aligned Mesochannels from Nonionic Micellar Solutions
}

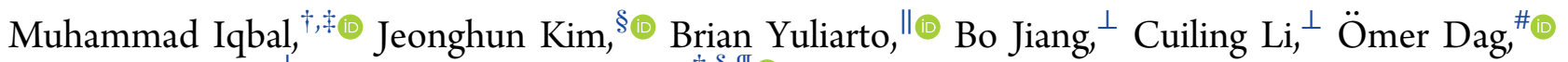 \\ Victor Malgras, ${ }^{* \perp}$ and Yusuke Yamauchi ${ }^{*}, \dagger, \S$, II०
}

${ }^{\dagger}$ Key Laboratory of Sensor Analysis of Tumor Marker (Ministry of Education), Shandong Key Laboratory of Biochemical Analysis, and Key Laboratory of Analytical Chemistry for Life Science in Universities of Shandong, College of Chemistry and Molecular Engineering, Qingdao University of Science and Technology (QUST), Qingdao 266042, China

${ }^{\ddagger}$ Department of Nanoscience and Nanoengineering, Faculty of Science and Engineering, Waseda University, 3-4-1 Okubo, Shinjuku, Tokyo 169-8555, Japan

${ }^{\S}$ School of Chemical Engineering and Australian Institute for Bioengineering and Nanotechnology (AIBN), The University of Queensland, Brisbane, Queensland 4072, Australia

"Department of Engineering Physics and Research Center for Nanoscience and Nanotechnology, Institut Teknologi Bandung, Ganesha 10, Bandung 40132, Indonesia

${ }^{\perp}$ International Research Center for Materials Nanoarchitectonics (WPI-MANA) and International Center for Young Scientists (ICYS), National Institute for Materials Science (NIMS), 1-1 Namiki, Tsukuba, Ibaraki 305-0044, Japan

\#Department of Chemistry, Bilkent University, Ankara 06800, Turkey

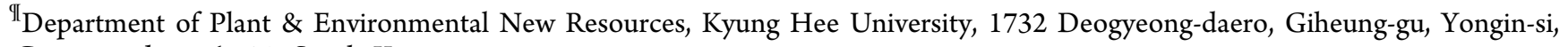
Gyeonggi-do 446-701, South Korea

\section{Supporting Information}

ABSTRACT: Mesoporous bimetallic palladium (Pd) alloy films with mesochannels perpendicularly aligned to the substrate are expected to show superior electrocatalytic activity and stability. The perpendicular mesochannels allow small molecules to efficiently access the active sites located not only at the surface but also within the film because of low diffusion resistance. When compared to pure Pd films, alloying with a secondary metal such as copper $(\mathrm{Cu})$ is cost-effective and promotes resistance against adventitious poisoning through intermediate reactions known to impair the electrocatalytic performance. Here, we report the synthesis of mesoporous $\mathrm{PdCu}$ films by electrochemical deposition in nonionic micellar solutions. The mesoporous structures are vertically aligned on the substrate, and the final content of $\mathrm{Pd}$ and $\mathrm{Cu}$ can be adjusted by tuning the initial precursor molar ratio in the electrolyte solution.

KEYWORDS: mesoporous materials, palladium, copper, alloys, vertically aligned mesochannels, nonionic surfactant, micelles

\section{INTRODUCTION}

Mesoporous materials are a promising platform for many applications, such as catalysis, energy conversion and storage, sensing, drug delivery, and adsorbtion. ${ }^{1-4}$ In particular, mesoporous metal films have the potential to enhance the oxidation reactions of small molecules and the oxygen reduction reactions by combining high catalytic activity and high surface area. ${ }^{5-7}$ Designing and fabricating mesoporous metal films with ordered mesochannels promoting the transport of guest molecule species is still a challenge. In particular, a well-ordered perpendicular mesochannel structure is expected to provide short migration distances for the reactants and products and increase the diffusion rate of the

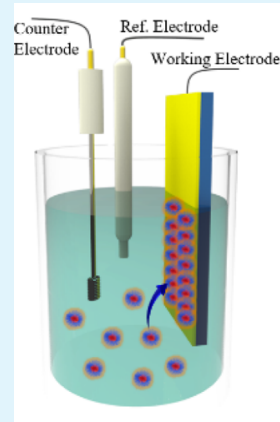

Electrodeposition System

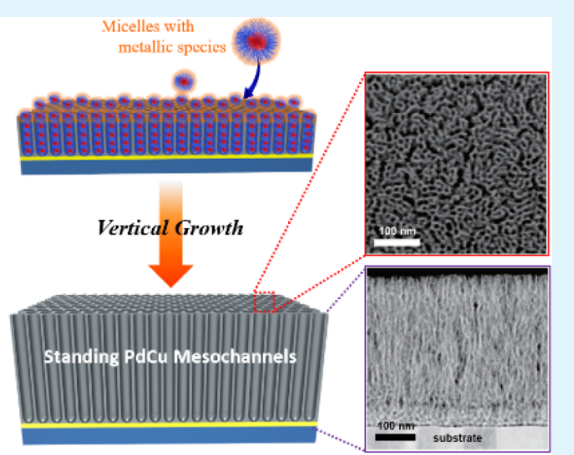

guest molecular species. ${ }^{8-10}$ However, the compositions of such architectures have been limited to metal oxides and carbons until now.

So far, the common approaches to fabricate mesoporous metal films have relied on hard-templating methods. ${ }^{11,12}$ Unfortunately, these techniques require much effort to grow metallic frameworks or nanoparticles inside the templates, while maintaining both the mesostructure and the morphology. Metallic films with uniform mesopores can also be fabricated

Received: August 9, 2018

Accepted: October 23, 2018

Published: November 14, 2018 
Scheme 1. Scheme Illustrating the Formation Mechanism of Vertically Aligned Mesochannels in the PdCu Films: (a) Micelle Formation and Three-Electrode System for Electrodeposition ; (b) Growth of PdCu Vertical Mesochannels by Micelles Decorated with Pd and Cu Metal Species
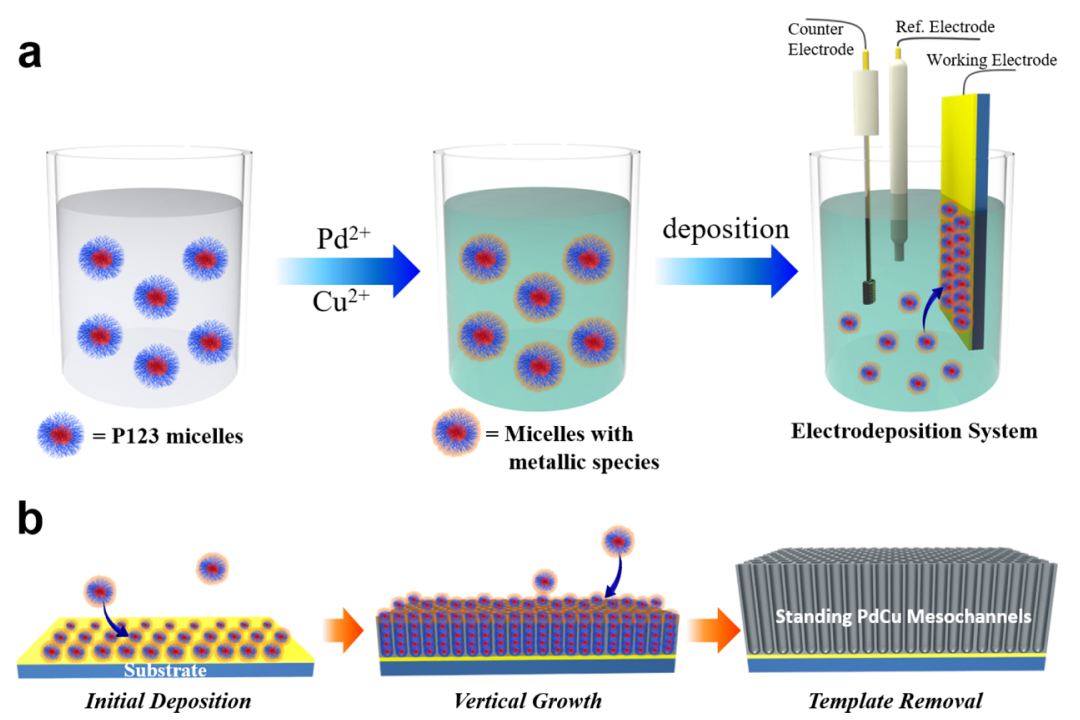

through liquid crystals- ${ }^{13,14}$ or micelle-assisted electrodeposition, ${ }^{15-18}$ yielding pores with a mean size within the range of 2-25 nm. In particular, mesoporous $\mathrm{Au}, \mathrm{Pt}$, and $\mathrm{Pd}$ films have been reported to showcase a better performance toward the electro-oxidation reaction. ${ }^{15,17,18}$ Soft-templating methods are more favorable because of their simplicity; they can be summed up in only two steps: direct growth of the metallic framework and template removal.

As the second most active noble metal-based electrocatalyst (after $\mathrm{Pt}$ ), the relative abundance of Pd makes it more suitable for further commercialization in low-temperature fuel cells, such as direct alcohol fuel cells (DAFCs). ${ }^{19,20}$ Unfortunately, the generation of intermediate products during the electrooxidation reaction of small molecules leads to a poisoning effect, which generally limits the activity and stability of Pdbased catalysts. ${ }^{21}$ Alloying Pd with a second metal (such as $\mathrm{Au}$, Ir, etc.) is effective in reducing the adsorption of intermediate reaction products onto the catalyst surface. ${ }^{22-24} \mathrm{Cu}$ is another secondary component from the $3 \mathrm{~d}$ transition metals, which also has the potential to provide a cost-effective material while enhancing the catalytic activity and stability of Pd-based electrocatalysts. Both experimental and theoretical studies reveal strong $\mathrm{Cu}-\mathrm{Pd}$ interactions and the capability of the bimetallic $\mathrm{PdCu}$ alloy to resist contamination. ${ }^{25-27}$ However, the fabrication of bimetallic $\mathrm{PdCu}$ alloy films with ordered mesochannels has been never reported.

Herein, we combine the advantages of both the bimetallic alloy and the perpendicular mesochannel structure, which not only lead to enhance the electrocatalytic activity and stability, but also to increase the diffusion rate of the guest molecule species. Although we previously reported the fabrication of mesoporous Pd films with vertically orientated mesochannels using cationic surfactants, ${ }^{17}$ in the present study, we extend this concept to an alloy, using a different surfactant system. We prepared $\mathrm{PdCu}$ films with mesochannels vertically aligned on the substrate by a simple nonionic surfactant (Pluronic P123) micelle-assisted electrodeposition process from aqueous electrolyte solutions (Scheme 1). The electrocatalytic activity of the as-deposited films toward ethanol oxidation was studied as the model reaction.

\section{EXPERIMENTAL SECTION}

Chemicals. Pluronic P123 and palladium black (PdB) were obtained from Sigma-Aldrich (USA). Ethanol and sulfuric acid were purchased from Nacalai Co. (Japan). Palladium(II) chloride, copper(II) sulfate, and potassium hydroxide were obtained from Wako Chemicals (Japan). All the chemicals were used without any prior treatment. Double-distilled water with a specific resistivity of 18.2 $\mathrm{M} \Omega \mathrm{cm}$ was provided by Merck Milli-Q water purification system.

Electrochemical Deposition. All the potential values in this work are reported versus $\mathrm{Ag} / \mathrm{AgCl}$, unless specified. Electrochemical deposition of mesoporous $\mathrm{PdCu}$ films was conducted utilizing an electrochemical station ( $\mathrm{CHI} 842 \mathrm{~B}$ electrochemical analyzer, $\mathrm{CHI}$ Instruments, USA). The conventional three-electrode system was employed: Au-coated Si wafer substrate $(3 \mathrm{~mm} \times 15 \mathrm{~mm}), \mathrm{Ag} / \mathrm{AgCl}$ electrode, and $\mathrm{Pt}$ wire were used as the working, reference, and counter electrodes, respectively. The Au conductive layer was deposited on the $\mathrm{Si}$ wafer by a sputtering technique $(\sim 20 \mathrm{~nm})$, with the $\mathrm{Ti}$ thin layer as the bonding element $(\sim 5 \mathrm{~nm})$. First, two aqueous stock solutions of $80 \mathrm{mM} \mathrm{PdCl}{ }_{2}$ and $80 \mathrm{mM} \mathrm{CuSO}$ were prepared (note that a few drops of $2 \mathrm{M} \mathrm{HCl}$ solution were added to avoid precipitation). The electrolyte consisted of a nonionic micellar solution prepared by dissolving 2.0 wt \% P123 (critical micelle concentration $(\mathrm{cmc}) 0.18 \mathrm{wt} \%$ at $293 \mathrm{~K}$ ) along with the metal precursors in water. The total concentration of the metal precursors was fixed to $40 \mathrm{mM}$. To optimize the system, various $\mathrm{Pd} / \mathrm{Cu}$ molar ratios (90:10, 80:20, 70:30, 60:40, and 50:50) and deposition times $(50,100,150$, and $200 \mathrm{~s})$ were tested, whereas the applied deposition potential was fixed at $-0.4 \mathrm{~V}$. To remove the soft templates, the asdeposited mesoporous $\mathrm{PdCu}$ films were rinsed thoroughly with double-distilled water and dried under a nitrogen gas flow. The obtained films were kept for further characterizations and electrochemical measurements. Mesoporous Pd films (without $\mathrm{Cu}$ ) and nonporous $\mathrm{PdCu}$ films (without P123) were also fabricated for comparison.

Characterization. The morphology of the mesoporous $\mathrm{PdCu}$ films was examined by field emission scanning electron microscopy (Hitachi SU-8230 at an accelerating voltage of $5 \mathrm{kV}$ ). Transmission electron microscopy (TEM), high-resolution TEM, high-angle annular dark field (HAADF) images, and energy-dispersive X-ray (EDX) mapping were obtained with a JEOL JEM-2100F at an accelerating voltage of $200 \mathrm{kV}$. Wide-angle X-ray diffraction (XRD) patterns were acquired with a Rigaku SmartLab X-ray diffractometer equipped with a $\mathrm{Cu} \mathrm{K} \alpha \mathrm{X}$-ray source. Two-dimensional (2D) grazing- 
incidence small-angle X-ray scattering (GI-SAXS) profiles were collected with a Rigaku NANO-Viewer (Microfocus rotating anode; $\mathrm{Cu} \mathrm{K} \alpha$ radiation; $40 \mathrm{kV}, 30 \mathrm{~mA}$ ) equipped with a camera length of $680 \mathrm{~mm}$. Ultraviolet-visible (UV-vis) absorption spectroscopy of the electrolyte solutions was performed by a JASCO V-7200. The surface elemental composition and electronic coordination state of the as-prepared $\mathrm{PdCu}$ films were analyzed by $\mathrm{X}$-ray photoelectron spectroscopy (XPS; PHI Quantera SXM; ULVAC-PHI; Al K $\alpha$ radiation). All XPS spectra were calibrated to the $C$ 1s peak at 285.0 $\mathrm{eV}$. To gather information about molar ratio on the final $\mathrm{PdCu}$ film product, inductively coupled plasma optical emission spectroscopy (ICP-OES) was carried out on a Hitachi model SPS3520UV-DD.

Electrochemical Measurements. All the electrochemical measurements were recorded on a $\mathrm{CHI} 842 \mathrm{~B}$ electrochemical analyzer ( $\mathrm{CH}$ Instrument, USA) with a standard three-electrode system. As-deposited $\mathrm{PdCu}$ films on Au-coated $\mathrm{Si}$ substrate was employed as the working electrode. $\mathrm{The} \mathrm{Ag} / \mathrm{AgCl}$ electrode and the standard calomel electrode (SCE) were used as the reference electrodes in acidic medium and basic medium electrolytes, respectively. A Pt wire was utilized as the counter electrode. The cyclic voltammetry $(\mathrm{CV})$ measurements were recorded in a $0.5 \mathrm{M}$ $\mathrm{H}_{2} \mathrm{SO}_{4}$ electrolyte at a scan rate of $50 \mathrm{mV} \mathrm{s}^{-1}$ between -0.2 and +1.2 $\mathrm{V}$. The electrocatalytic performance toward the ethanol oxidation reaction was recorded in $1.0 \mathrm{M} \mathrm{KOH}$ containing $1.0 \mathrm{M} \mathrm{C}_{2} \mathrm{H}_{5} \mathrm{OH}$ in a potential range from -0.8 to $0.3 \mathrm{~V}$ (vs SCE). All the CV measurements were repeated three times for each sample. Amperometric $i-t$ curves were recorded at a fixed potential of -0.2 $\mathrm{V}$ (vs SCE) for $1200 \mathrm{~s}$ in $1.0 \mathrm{M} \mathrm{KOH}$ containing $1.0 \mathrm{M} \mathrm{C}_{2} \mathrm{H}_{5} \mathrm{OH}$ to study the stability. Other working electrodes were prepared for performance comparison: mesoporous $\mathrm{Pd}$ and nonporous $\mathrm{PdCu}$ films deposited on an Au-coated $\mathrm{Si}$ substrate and commercial palladium black (PdB). A $5 \mu \mathrm{L}$ of $1 \mathrm{mg} \mathrm{mL}^{-1} \mathrm{PdB}$ was drop-cast on a polished glassy carbon electrode followed by coating with a Nafion resin solution and dried in an ambient atmosphere prior to electrochemical measurements.

\section{RESULTS AND DISCUSSION}

A conventional three-electrode system was employed for the deposition of mesoporous PdCu films: Au-coated Si wafer substrate, $\mathrm{Ag} / \mathrm{AgCl}$ electrode, and Pt wire were used as the working, reference, and counter electrodes, respectively. The electrolyte solution consisted of a nonionic micellar solution prepared by dissolving $2.0 \mathrm{wt} \% \mathrm{P} 123$ ( $\mathrm{cmc} 0.18 \mathrm{wt} \%$ at 293 $\mathrm{K})$ along with the metal precursors $\left(\mathrm{PdCl}_{2}\right.$ and $\left.\mathrm{CuSO}_{4}\right)$ in double-distilled water. To optimize the system, various $\mathrm{Pd} / \mathrm{Cu}$ molar ratios (90:10, 80:20, 70:30, 60:40, and 50:50) and deposition times $(50,100,150$, and $200 \mathrm{~s})$ were tested, whereas the applied deposition potential was fixed to $-0.4 \mathrm{~V}$. To remove the soft templates, the as-deposited mesoporous $\mathrm{PdCu}$ films were rinsed thoroughly with double-distilled water and dried under a nitrogen gas flow. For comparison, mesoporous $\mathrm{Pd}$ films (without $\mathrm{Cu}$ ) and nonporous $\mathrm{PdCu}$ films (without P123) were also fabricated (Figure S1).

According to the previously reported scattering data obtained by small-angle neutron scattering, it is proved that the nonionic surfactant, Pluronic P123, forms spherical-shaped micelles in water with an average diameter ca. $13 \mathrm{~nm}$ (Figure S2). ${ }^{16}$ The micelle core consists of a hydrophobic moiety (polypropylene oxide, PPO block) and its shell of a hydrophilic moiety (polyethylene, PEO block). Even after the addition of metal precursors, the average diameter of the spherical-shaped micelles does not change significantly. To study the interactions among the solvent, micelles, and the metal precursors, optical absorption spectroscopy was carried out on various aqueous solutions (Figure S3). The UV-vis absorption study shows the existence of two metal aqua complexes: $\left[\mathrm{Cu}\left(\mathrm{H}_{2} \mathrm{O}\right)_{x}\right]^{2+}$ ions and $\left[\mathrm{PdCl}_{4-x}\left(\mathrm{H}_{2} \mathrm{O}\right)_{x}\right]^{(-2+x)}$ ions, where the $\mathrm{Cl}^{-}$ions are exchanged with the water molecules. These water-coordinated $\mathrm{Pd}$ and $\mathrm{Cu}$ ions in the electrolyte solutions interact with the PEO groups of the micelles through hydrogen bonding.

The potential applied during the electrodeposition of mesoporous $\mathrm{PdCu}$ films was determined after studying the reduction potential of the $\mathrm{Pd}$ and $\mathrm{Cu}$ ions in the electrolyte solution by linear sweep voltammetry (LSV) (Figure 1). In our

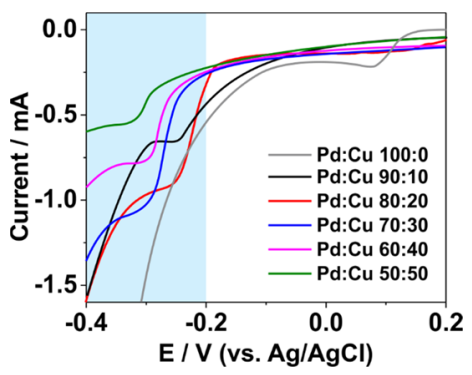

Figure 1. LSV curves with the Au-coated Si substrate as the working electrode (geometrical area of $0.18 \mathrm{~cm}^{2}$ ) recorded at a scan rate of 10 $\mathrm{mV} \mathrm{s}^{-1}$ from electrolyte solutions containing micelles and various $\mathrm{Pd} /$ $\mathrm{Cu}$ precursor molar ratios. The precursor concentrations in the electrolyte solutions were fixed at $40 \mathrm{mM}$.

previous work, we found that the reduction potential to carry out the reduction of $\mathrm{Pd}$ ions into $\mathrm{Pd}(0)$ in an electrolyte solution containing micelles was around $0.0 \mathrm{~V} .{ }^{16}$ In accordance with the LSV plot in Figure 1, the reduction of $\mathrm{Pd}$ and $\mathrm{Cu}$ ions into $\mathrm{PdCu}$ alloys starts at ca. $-0.2 \mathrm{~V}$. The formation of hydrogen bubbles is observed beyond $-0.4 \mathrm{~V}$. The electrodeposition of $\mathrm{PdCu}$ films was then carried out at $-0.2,-0.3$, and $-0.4 \mathrm{~V}$ to ensure the reduction of both $\mathrm{Pd}$ and $\mathrm{Cu}$ precursors, as well as to avoid the detrimental effects caused by the generation of hydrogen bubbles on the film structure. The optimal deposition voltage was determined after observing the morphology of the films from the cross-sectional and top scanning electron microscopy (SEM) as well as GI-SAXS images (Figure 2). The SEM images reveal that carrying out the deposition at $-0.4 \mathrm{~V}$ leads to a smooth and uniform structure (Figure 3a,b), unlike the films deposited at -0.2 and $-0.3 \mathrm{~V}$ (Figure 2). The 2D scattering profiles of the films deposited at -0.2 and $-0.3 \mathrm{~V}$ show a half-ring pattern, which indicates that the pores are randomly packed, whereas clear spots can be observed on the left and right sides of the beam for the film deposited at $-0.4 \mathrm{~V}$, indicating well-ordered mesochannels vertically aligned on the substrate (A detailed discussion on the obtained GI-SAXS spots is given in a later section.). ${ }^{28,29}$ The cross-sectional TEM and HAADFscanning transmission electron microscopy (STEM) images of the mesoporous $\mathrm{Pd}_{81} \mathrm{Cu}_{19}$ film show that all the mesochannels are standing on the substrate (Figure $3 c, d$ ).

Our method enables a simple and accurate approach to tune the metal composition of the final film, which was found to closely match the initial precursor molar ratio (Table 1). Mesoporous $\mathrm{PdCu}$ films deposited at $-0.4 \mathrm{~V}$ were synthesized with different $\mathrm{Pd} / \mathrm{Cu}$ molar ratios. According to the ICP-OES analysis, the samples are designated as $\mathrm{Pd}_{x} \mathrm{Cu}_{100-x}$, where $x$ and $100-x$ correspond to the atomic percentage of $\mathrm{Pd}$ and $\mathrm{Cu}$, respectively. It is worth mentioning that the film thickness can simply be increased with the deposition time, without affecting the integrity of the mesoporous structure (Figure 4). The top 


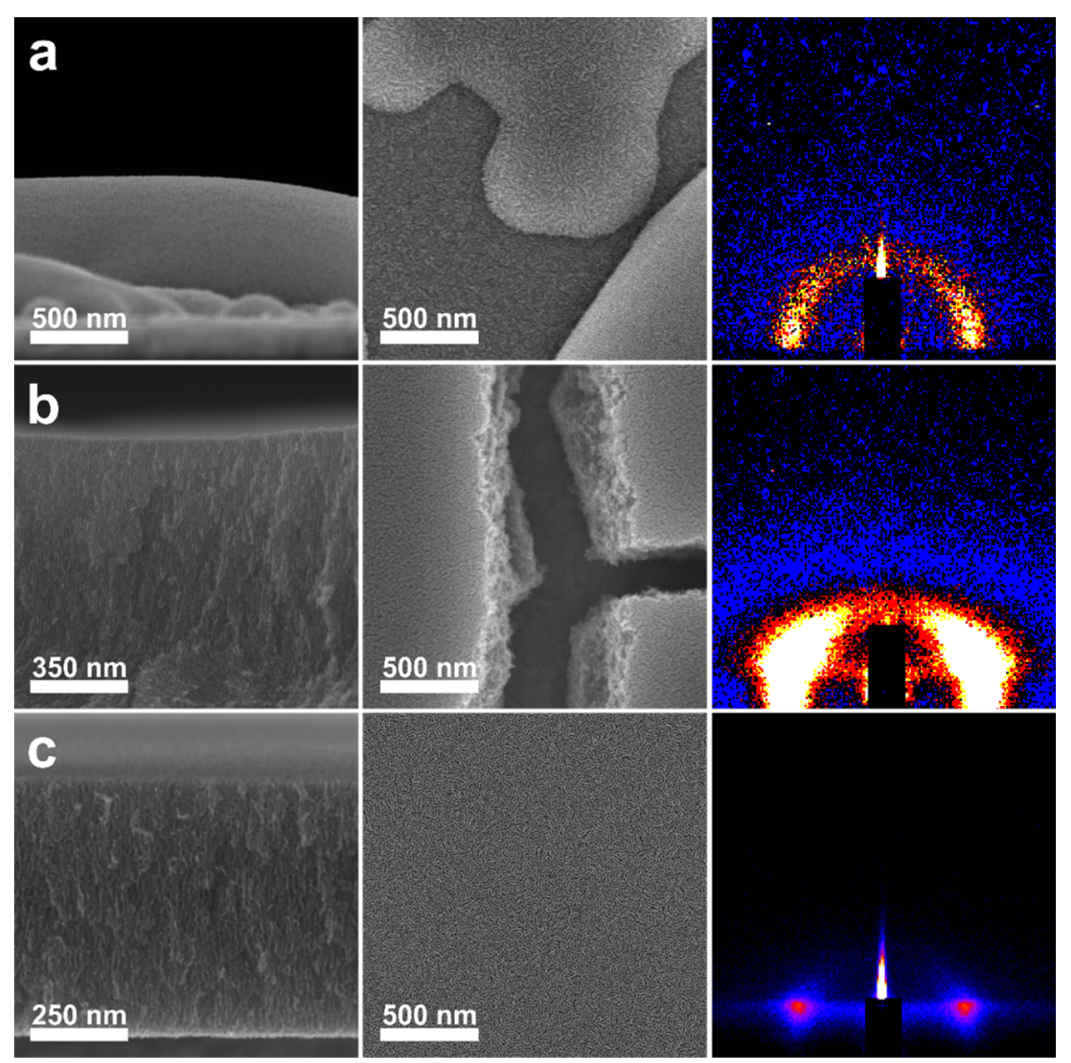

Figure 2. Cross-sectional (left panel), low-magnification top-view SEM images (center panel), and the corresponding 2D GI-SAXS profiles (right panel) of the mesoporous $\mathrm{Pd}_{81} \mathrm{Cu}_{19}$ films deposited at (a) -0.2 , (b) -0.3 , and (c) $-0.4 \mathrm{~V}$, respectively.

view of the mesoporous $\mathrm{Pd}_{x} \mathrm{Cu}_{100-x}$ films observed by SEM reveals the pores distributed uniformly through the entire surface (Figures 3a,b and S4). The average pore size, statistically calculated from over 100 pores, was found to the range between 7 and $9 \mathrm{~nm}$. GI-SAXS was further employed to characterize the pore ordering and periodicity of the films with various $\mathrm{Pd} / \mathrm{Cu}$ ratios. The half ring (halo) observed on the $2 \mathrm{D}$ scattering profile of the pure $\mathrm{Pd}$ film indicates the existence of isotropic periodicity, whereas the two spots observed for the alloyed films suggest that the mesochannels are aligned perpendicularly to the substrate (Figure 5). ${ }^{28,29}$ The samples showing spots overlapping with a pseudo-half ring consist of aligned channels with a mild degree of isotropy. As mass transport is expected to be favored in well-aligned mesochannels, electrocatalytic activity should decrease as the degree of isotropy increases. The converted $2 \mathrm{D}$ scattering (inplane) profiles of each mesoporous $\mathrm{Pd}_{x} \mathrm{Cu}_{100-x}$ film sample show a distinct peak located between $q=0.4$ and $0.5 \mathrm{~nm}^{-1}$ (Figure 5). Although all the mesochannels in the alloyed films are vertically aligned, the in-plane ordering is not perfectly arranged. Therefore, the resulting pore-to-pore distance can be roughly estimated from the $d$ values of the in-plane spots. The pore-to-pore distances are 12.4, 12.4, 12.6, 13.0, and $13.3 \mathrm{~nm}$ for $\mathrm{Pd}_{91} \mathrm{Cu}_{9}, \mathrm{Pd}_{81} \mathrm{Cu}_{19}, \mathrm{Pd}_{71} \mathrm{Cu}_{29}, \mathrm{Pd}_{59} \mathrm{Cu}_{41}$, and $\mathrm{Pd}_{49} \mathrm{Cu}_{51}$, respectively. These values are well-supported by the top surface SEM images (Figure S4).

In light of these results, we propose the following mechanism for the formation of mesochannels in the $\mathrm{PdCu}$ films: the hydrophobic moiety of P123 in the electrolyte solution maintains the stability of the micelles, whereas the hydrophilic moiety can solvate or attract the metal ion complex species through hydrogen-bonding $\left[-\mathrm{CH}_{2} \mathrm{CH}_{2} \mathrm{O}-\cdots \mathrm{H}_{2} \mathrm{O}-\right.$
$\mathrm{Cu}(\mathrm{II})$ or $\left.-\mathrm{CH}_{2} \mathrm{CH}_{2} \mathrm{O}-\cdots \mathrm{H}_{2} \mathrm{O}-\mathrm{Pd}(\mathrm{II})\right]$ and electrostatic interactions. Notice also that the $\mathrm{pH}$ of the solution is around 2 , which means that the $\mathrm{SO}_{4}{ }^{2-}$ ions are protonated $\left(\mathrm{HSO}_{4}{ }^{-}\right)$; this chaotropic agent further enhances the micellization of P123 (increases the micelle concentration in the media). As the charge of the $\mathrm{Pd}$ (II) complexes varies from -2 to +2 with increasing the water content in the coordination sphere and also the $\mathrm{Cu}^{2+}$ ion coordination sphere is water, the presence of coordinated water is important for the assembly and also for interaction of metal ions with the ethylene oxide domains for accumulating metal ions $[\mathrm{Pd}(\mathrm{II})$ as well as $\mathrm{Cu}(\mathrm{II})]$ in and around the micelles. When a potential is applied on the Aucoated $\mathrm{Si}$ substrate (working electrode), the generated electromotive force attracts the $\mathrm{Pd}(\mathrm{II}) / \mathrm{Cu}(\mathrm{II})$ complex ions (along with the micelles) toward the working electrode, where they are reduced to their metallic state. The basis for the reductive and transformative reaction is the current, which passed through the working electrode. ${ }^{30}$ Note that the applied deposition potential in this work was $-0.4 \mathrm{~V}$ versus $\mathrm{Ag} / \mathrm{AgCl}$ and that the standard reduction potentials of $\left[\mathrm{PdCl}_{4}\right]^{2-} / \mathrm{Pd}$ and $\mathrm{Cu}^{2+} / \mathrm{Cu}$ are 0.591 and $0.342 \mathrm{~V}$ versus $\mathrm{SHE}$, respectively. ${ }^{31}$ As a result, the films are electrochemically deposited on the substrate, with the $\mathrm{PdCu}$ alloy crystallizing around the micelles, forming the mesochannels (Scheme 1).

During the metallic growth, the spherical micelles fuse together to form cylindrical micelles, thereby leading to the assembly of mesochannels aligned perpendicularly to the substrate. In general, the fusion of spherical triblock copolymer micelles into rodlike micelles is affected by the temperature and the quality of the solvent (i.e., addition of ethanol, acid, and salts)..$^{32}$ In some cases, the sphere-to-rod transition can be observed by adjusting the polymer-to-precursor ratio. ${ }^{33}$ 


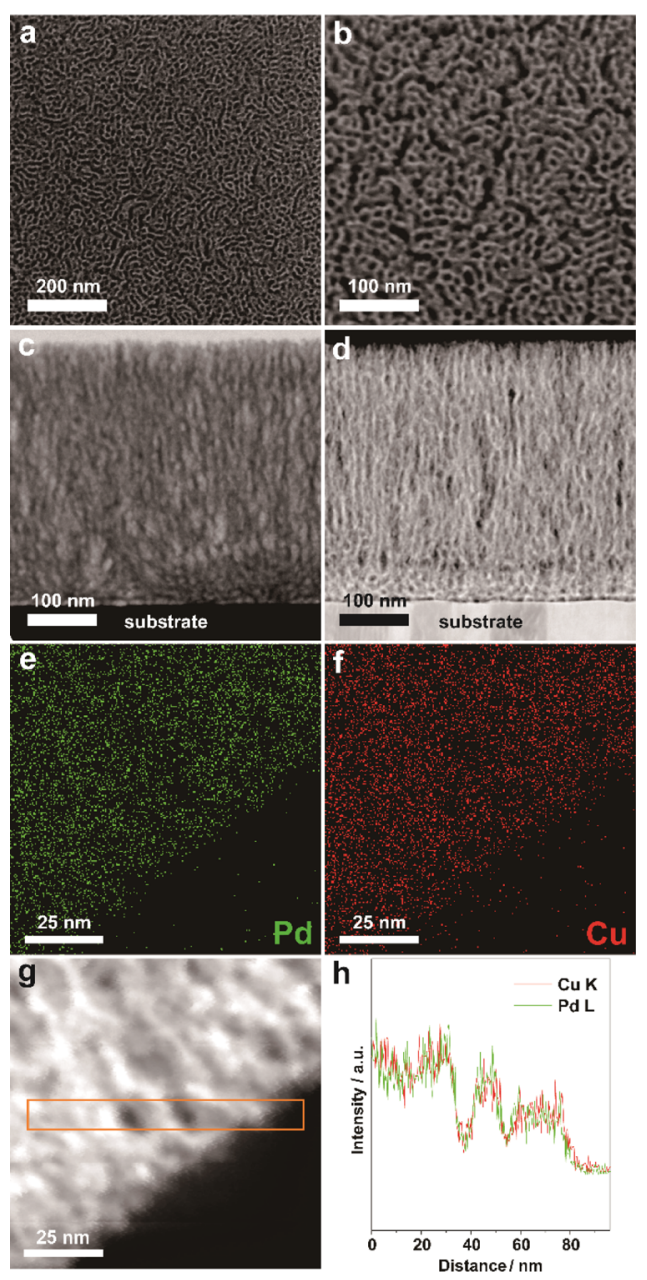

Figure 3. (a,b) Top-view SEM images with different magnifications, (c) TEM and (d) HAADF-STEM cross-sectional images of the mesoporous $\mathrm{Pd}_{81} \mathrm{Cu}_{19}$ films with the mesochannels aligned perpendicularly to the substrate. (e,f) Elemental mapping images, (g) HAADF-STEM image, and (h) line-scanning compositional profile of the mesoporous $\mathrm{Pd}_{49} \mathrm{Cu}_{51}$ films from the rectangle area indicated in $(\mathrm{g})$.

Table 1. Summary of the $\mathrm{Pd}$ and $\mathrm{Cu}$ Molar Ratios in Both the Precursor Electrolytes and the Films ${ }^{a}$

\begin{tabular}{ccc} 
& \multicolumn{2}{c}{$\mathrm{Pd} / \mathrm{Cu}$ molar ratios } \\
\cline { 2 - 3 } sample & electrolyte solution & deposited films \\
$\mathrm{Pd}_{91} \mathrm{Cu}_{9}$ & $90: 10$ & $91: 9$ \\
$\mathrm{Pd}_{81} \mathrm{Cu}_{19}$ & $80: 20$ & $81: 19$ \\
$\mathrm{Pd}_{71} \mathrm{Cu}_{29}$ & $70: 30$ & $71: 29$ \\
$\mathrm{Pd}_{59} \mathrm{Cu}_{41}$ & $60: 40$ & $59: 41$ \\
$\mathrm{Pd}_{49} \mathrm{Cu}_{51}$ & $50: 50$ & $49: 51$
\end{tabular}

${ }^{a}$ ICP-OES was utilized to measure accurately the mass of Pd and $\mathrm{Cu}$ in the final films.

However, in the present study, this transition does not seem to be affected by these factors. As shown in Figure 2, the quality of the mesoporous structures is mostly affected by the deposition potential. At low voltage (slow deposition rate), the micelles tend to remain spherical. Therefore, it is assumed that the fusion of spherical micelles into rodlike micelles occurs at a faster deposition rate $(-0.4 \mathrm{~V})$. In addition, the hydrophobicity of the substrate should have negligible interactions with the hydrophilic moiety of the micelles, thus
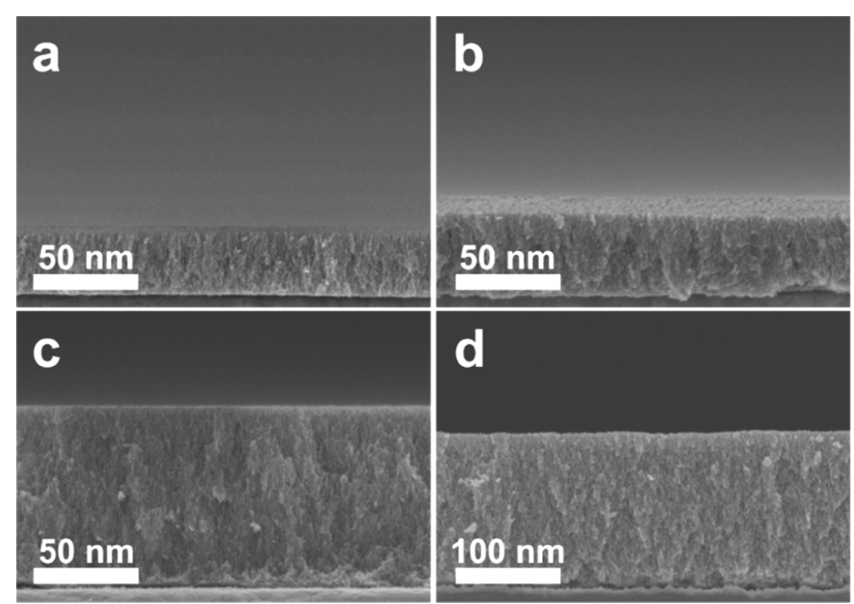

Figure 4. Cross-sectional SEM images of the mesoporous $\mathrm{Pd}_{81} \mathrm{Cu}_{19}$ films deposited with various deposition times: (a) 50, (b) 100, (c) 200, and (d) $400 \mathrm{~s}$.

accommodating the growth of the mesochannels along the vertical direction. ${ }^{28,29}$ The $\mathrm{Pd}-\mathrm{Cu}$ alloy oxidation states in the framework were confirmed by XRD, XPS, and elemental mapping (Figures S5-S8, Table S1). The Pd and Cu elements are spread throughout the metallic pore walls, as confirmed by EDX elemental mapping and line-scanning compositional profile (Figure $3 \mathrm{e}-\mathrm{h}$ ).

The electrochemical active surface area (ECSA) of Pd-based electrocatalysts can be estimated by $\mathrm{CV}$ and CO-stripping experiment (Figures S9, S10 and Table S2). The catalyst films were studied for the electro-oxidation reaction of ethanol molecules. On the Pd mass-normalized CV curve of the mesoporous alloyed films shown in Figure S11a, the clear anodic peaks observed in the forward scan are a signature of the oxidation of chemisorbed ethanol. ${ }^{34}$ The $\mathrm{Pd}_{81} \mathrm{Cu}_{19}$ film showed a superior mass-normalized peak current density $(2.77$ A $\mathrm{mg}^{-1}$ ), compared to the other alloyed films and also compared to the three control and benchmark samples: mesoporous $\mathrm{Pd}$ films $\left(1.75 \mathrm{~A} \mathrm{mg}^{-1}\right)$, nonporous $\mathrm{Pd}_{81} \mathrm{Cu}_{19}$ films (1.01 $\left.\mathrm{A} \mathrm{mg}^{-1}\right)$, and $\mathrm{PdB}\left(0.71 \mathrm{~A} \mathrm{mg}^{-1}\right)$ (Figure S11a). Even when normalized by their respective surface areas, the mesoporous $\mathrm{Pd}_{81} \mathrm{Cu}_{19}$ film still exhibited the highest peak current density among all (Figure S11b). The onset potential of the mesoporous $\mathrm{Pd}_{81} \mathrm{Cu}_{19}$ film measured by LSV was more negative than that of the control and benchmark samples (Figure 6), showcasing the importance of both the bimetallic synergy and the aligned mesochannels in enhancing the ethanol oxidation activity. The stability of the electrocatalyst is an important factor for the ethanol oxidation reaction. Therefore, the mesoporous $\mathrm{Pd}_{81} \mathrm{Cu}_{19}$ films and control samples were examined for their stability. The $\mathrm{Pd}_{81} \mathrm{Cu}_{19}$ film revealed a superior catalytic stability when investigated by the amperometric $i-t$ technique at a constant potential of $-0.2 \mathrm{~V}$ (vs SCE) for $1200 \mathrm{~s}$ (Figure 7).

The feature of the standing mesochannels of $\mathrm{Pd}_{81} \mathrm{Cu}_{19}$ films was also investigated by carrying out $\mathrm{CV}$ toward ethanol oxidation at various scan rates (Figure $8 \mathrm{a}-\mathrm{c}$ ). The diffusion characteristics of the guest molecular species can be observed from the relationship between a series of square root of the scan rates and the mass activity obtained at the respective scan rates. ${ }^{35}$ This was achieved by using the parameters extracted from the $\mathrm{CV}$ profiles of mesoporous $\mathrm{Pd}$ with cage-type mesopores, mesoporous $\mathrm{Pd}_{81} \mathrm{Cu}_{19}$ with vertically oriented 

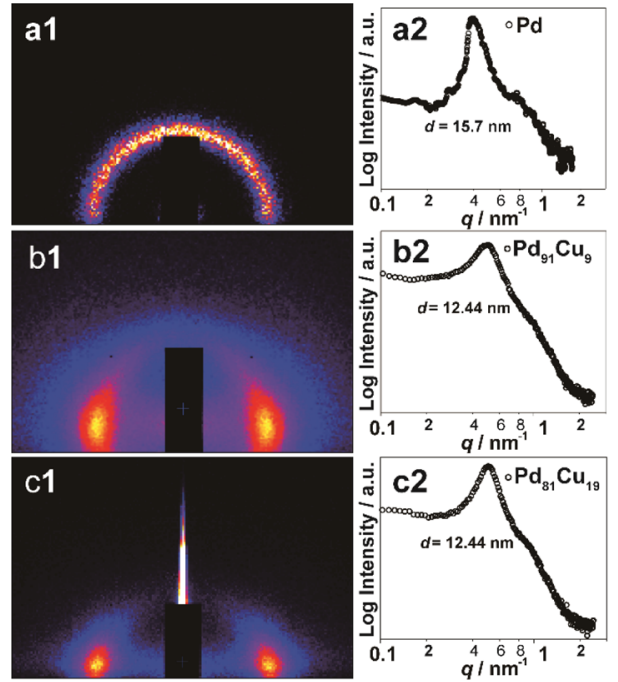
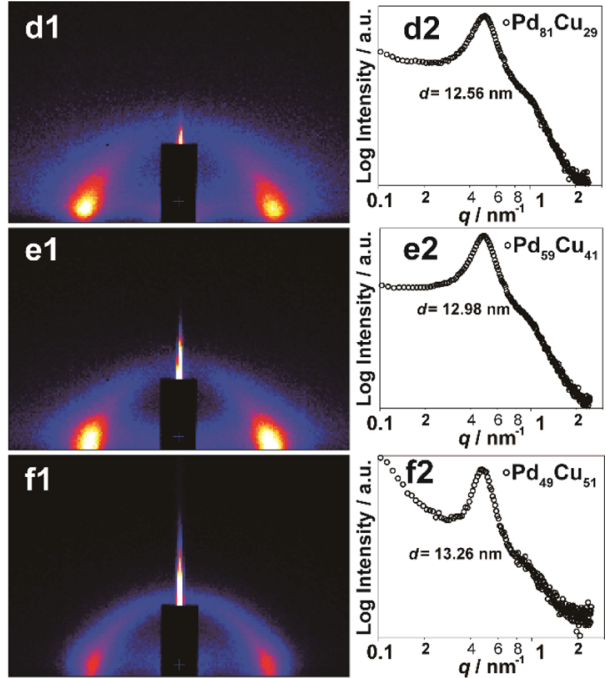

Figure 5. $(\mathrm{a} 1-\mathrm{f} 1) 2 \mathrm{D}$ scattering profiles and $(\mathrm{a} 2-\mathrm{f} 2)$ in-plane converted profiles of the mesoporous $\mathrm{Pd}_{x} \mathrm{Cu}_{100-x}$ films obtained by GI-SAXS.

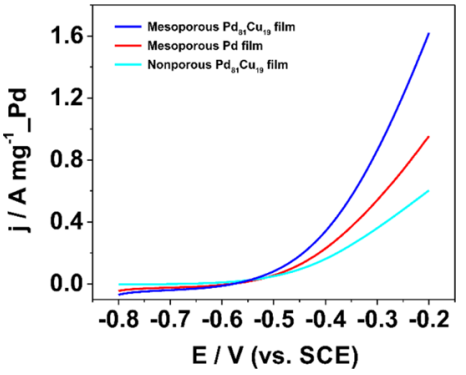

Figure 6. Pd mass-normalized LSV measurement of the mesoporous $\mathrm{Pd}_{81} \mathrm{Cu}_{19}$, mesoporous $\mathrm{Pd}$, and nonporous $\mathrm{Pd}_{81} \mathrm{Cu}_{19}$ films in $1.0 \mathrm{M}$ $\mathrm{KOH}$ containing $1.0 \mathrm{M} \mathrm{C}_{2} \mathrm{H}_{5} \mathrm{OH}$. The curves were obtained at a scan rate of $50 \mathrm{mV} \mathrm{s}^{-1}$. All the tested film electrodes have the same geometrical area $\left(0.18 \mathrm{~cm}^{2}\right)$.
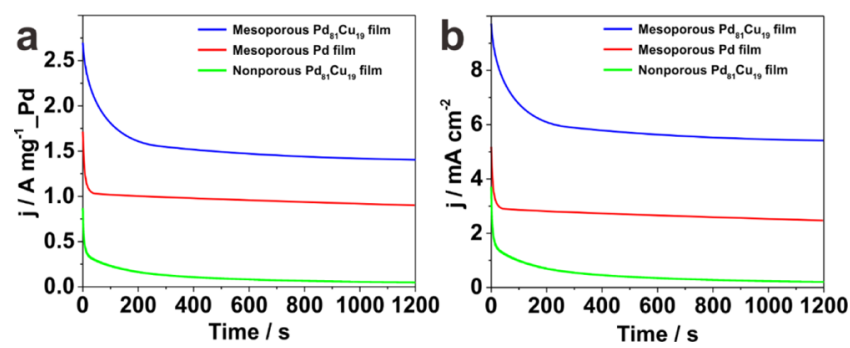

Figure 7. (a) Pd mass-normalized and (b) ECSA-normalized amperometric $i-t$ curves of the mesoporous $\mathrm{Pd}_{81} \mathrm{Cu}_{19}$, mesoporous $\mathrm{Pd}$, and nonporous $\mathrm{Pd}_{81} \mathrm{Cu}_{19}$ films in $1.0 \mathrm{M} \mathrm{KOH}$ containing $1.0 \mathrm{M}$ $\mathrm{C}_{2} \mathrm{H}_{5} \mathrm{OH}$ for $1200 \mathrm{~s}$ at a constant potential of $-0.2 \mathrm{~V}$ (vs SCE).

mesochannels, and nonporous $\mathrm{Pd}_{81} \mathrm{Cu}_{19}$ films. The gradient of the forward oxidation peak current densities against the square root of the scan rate was larger for the mesoporous $\mathrm{Pd}_{81} \mathrm{Cu}_{19}$ film than those of the mesoporous $\mathrm{Pd}$ and nonporous $\mathrm{Pd}_{81} \mathrm{Cu}_{19}$ films (Figure 8d). This phenomenon suggests that the diffusion efficiency of ethanol molecules inside the standing mesochannels is higher than that in the cage-type pores and nonporous film structures. ${ }^{36-39}$

\section{CONCLUSIONS}

In this work, mesoporous $\mathrm{PdCu}$ films with mesochannel structure have been successfully synthesized by surfactant
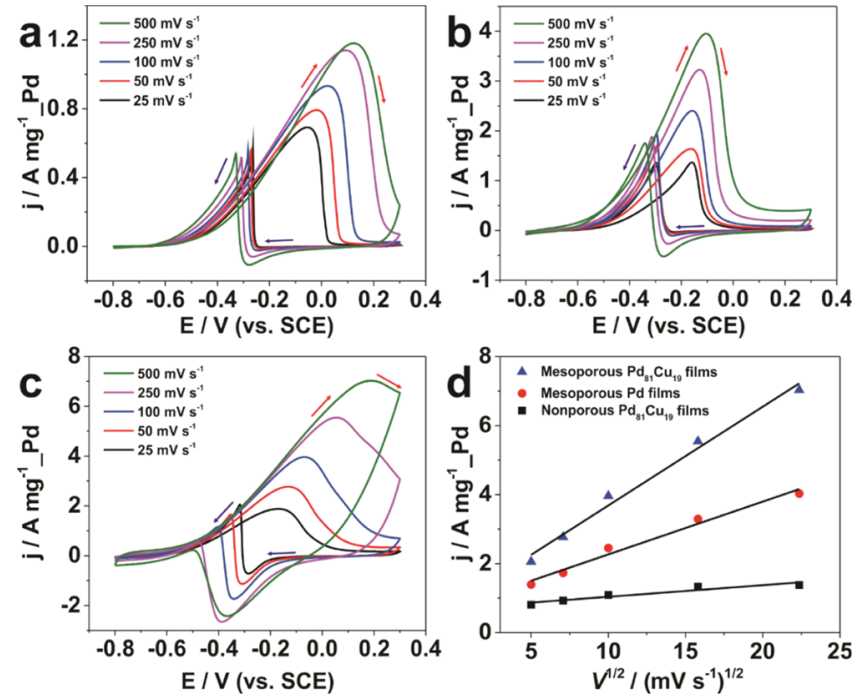

Figure 8. $(\mathrm{a}-\mathrm{c})$ Cyclic voltammetry of (a) nonporous $\mathrm{Pd}_{81} \mathrm{Cu}_{19}$, (b) mesoporous $\mathrm{Pd}$, and (c) mesoporous $\mathrm{Pd}_{81} \mathrm{Cu}_{19}$ films in $1.0 \mathrm{M} \mathrm{KOH}$ containing $1.0 \mathrm{M} \mathrm{C}_{2} \mathrm{H}_{5} \mathrm{OH}$ at various scan rates. (d) Forward oxidation peak current density (mass activity) as a function of the square root of the scan rate for nonporous $\mathrm{Pd}_{81} \mathrm{Cu}_{19}$, mesoporous $\mathrm{Pd}$, and mesoporous $\mathrm{Pd}_{81} \mathrm{Cu}_{19}$ films.

micelle-assisted electrodeposition. The mesoporous structure has a high degree of vertical alignment, as evidenced by GISAXS characterization, thus promoting the accessibility of the surface-active sites and lowering the diffusion resistance of the reactant. Also, the presence of $\mathrm{Cu}$ atoms in the bimetallic system reduces the capability of the surface to accommodate poisoning products from intermediate reactions. Although the concept of soft-templated electrodeposition of mesoporous metallic alloy films is still at its early stage, it already demonstrates promising outputs, such as for DAFCs devices. In a broader context, the soft-templating approach can be exploited to prepare novel metal nanostructures which have been never reported. ${ }^{40-44}$ 


\section{ASSOCIATED CONTENT}

\section{S Supporting Information}

The Supporting Information is available free of charge on the ACS Publications website at DOI: 10.1021/acsami.8b13662.

SEM images of mesoporous $\mathrm{Pd}$ films and nonporous $\mathrm{Pd}_{81} \mathrm{Cu}_{19}$ films; schematic model representing P123 micelles in water; UV-Vis absorption spectra of aqueous solutions containing $\mathrm{PdCl}_{2}, \mathrm{CuSO}_{4}$, and $\mathrm{PdCl}_{2}+\mathrm{CuSO}_{4}$; diffraction patterns of the mesoporous $\mathrm{Pd}_{x} \mathrm{Cu}_{100-x}$ films; relationship between the $\mathrm{Cu}$ content in the as-deposited films and the $d$-spacings according to Vegard's law and the XRD diffraction patterns; HRTEM images of the mesoporous $\mathrm{Pd}_{81} \mathrm{Cu}_{19}$ and $\mathrm{Pd}_{49} \mathrm{Cu}_{51}$ films; first and second cycle CO-stripping voltammetry of mesoporous $\mathrm{Pd}_{91} \mathrm{Cu}_{9}, \mathrm{Pd}_{81} \mathrm{Cu}_{19}, \mathrm{Pd}_{71} \mathrm{Cu}_{29}, \mathrm{Pd}_{59} \mathrm{Cu}_{41}$, and $\mathrm{Pd}_{49} \mathrm{Cu}_{51}$ films; and Pd mass-normalized and ECSAnormalized $\mathrm{CV}$ curves of $\mathrm{PdB}$, nonporous $\mathrm{Pd}_{81} \mathrm{Cu}_{19}$ films, mesoporous $\mathrm{Pd}, \mathrm{Pd}_{91} \mathrm{Cu}_{9}, \mathrm{Pd}_{81} \mathrm{Cu}_{19}, \mathrm{Pd}_{71} \mathrm{Cu}_{29}$, $\mathrm{Pd}_{59} \mathrm{Cu}_{41}$, and $\mathrm{Pd}_{49} \mathrm{Cu}_{51}$ films (PDF)

\section{AUTHOR INFORMATION}

\section{Corresponding Authors}

*E-mail: malgras.victor@nims.go.jp (V.M.).

*E-mail: y.yamauchi@uq.edu.au (Y.Y.).

\section{ORCID}

Muhammad Iqbal: 0000-0001-9944-0329

Jeonghun Kim: 0000-0001-6325-0507

Brian Yuliarto: 0000-0003-0662-7923

Ömer Dag: 0000-0002-1129-3246

Yusuke Yamauchi: 0000-0001-7854-927X

\section{Author Contributions}

The manuscript was written through contributions of all authors. All authors have given approval to the final version of the manuscript.

\section{Notes}

The authors declare no competing financial interest.

\section{ACKNOWLEDGMENTS}

This work was supported by the Australian Research Council (ARC) Future Fellow (FT150100479), JSPS KAKENHI (17H05393 and 17K19044), and the research fund by the Suzuken Memorial Foundation. This work was partially performed at the Queensland node of the Australian National Fabrication Facility, a company established under the National Collaborative Research Infrastructure Strategy to provide nano- and micro-fabrication facilities for Australian researchers. M. I. would like to thank the Indonesia Endowment Fund for Education (LPDP) for the financial support.

\section{REFERENCES}

(1) Ariga, K.; Vinu, A.; Yamauchi, Y.; Ji, Q.; Hill, J. P. Nanoarchitectonics for Mesoporous Materials. Bull. Chem. Soc. Jpn. 2012, 85, 1-32.

(2) Wagner, T.; Haffer, S.; Weinberger, C.; Klaus, D.; Tiemann, M. Mesoporous Materials as Gas Sensors. Chem. Soc. Rev. 2013, 42, 4036-4053.

(3) Hartmann, M. Ordered Mesoporous Materials for Bioadsorption and Biocatalysis. Chem. Mater. 2005, 17, 4577-4593.

(4) Wu, Z.; Zhao, D. Ordered Mesoporous Materials as Adsorbents. Chem. Commun. 2011, 47, 3332-3338.
(5) Yamauchi, Y.; Kuroda, K. Rational Design of Mesoporous Metals and Related Nanomaterials by a Soft-Template Approach. Chem.Asian J. 2008, 3, 664-676.

(6) Attard, G. S.; Bartlett, P. N.; Coleman, N. R. B.; Elliott, J. M.; Owen, J. R.; Wang, J. H. Mesoporous Platinum Films from Lyotropic Liquid Crystalline Phases. Science 1997, 278, 838-840.

(7) Malgras, V.; Ataee-Esfahani, H.; Wang, H.; Jiang, B.; Li, C.; Wu, K. C.-W.; Kim, J. H.; Yamauchi, Y. Nanoarchitectures for Mesoporous Metals. Adv. Mater. 2016, 28, 993-1010.

(8) Teng, Z.; Zheng, G.; Dou, Y.; Li, W.; Mou, C.-Y.; Zhang, X.; Asiri, A. M.; Zhao, D. Highly Ordered Mesoporous Silica Films with Perpendicular Mesochannels by a Simple Stöber-Solution Growth Approach. Angew. Chem., Int. Ed. 2012, 51, 2173-2177.

(9) Walcarius, A.; Sibottier, E.; Etienne, M.; Ghanbaja, J. Electrochemically Assisted Self-Assembly of Mesoporous Silica Thin Films. Nat. Mater. 2007, 6, 602-608.

(10) Lin, M.-L.; Huang, C.-C.; Lo, M.-Y.; Mou, C.-Y. Well-Ordered Mesoporous Carbon Thin Film with Perpendicular Channels: Application to Direct Methanol Fuel Cell. J. Phys. Chem. C 2008, $112,867-873$.

(11) Wang, D.; Zhou, W. L.; McCaughy, B. F.; Hampsey, J. E.; Ji, X.; Jiang, Y.-B.; Xu, H.; Tang, J.; Schmehl, R. H.; O’Connor, C.; Brinker, C. J.; Lu, Y. Electrodeposition of Metallic Nanowire Thin Films Using Mesoporous Silica Templates. Adv. Mater. 2003, 15, 130-133.

(12) Wang, D.; Luo, H.; Kou, R.; Gil, M. P.; Xiao, S.; Golub, V. O.; Yang, Z.; Brinker, C. J.; Lu, Y. A General Route to Macroscopic Hierarchical 3D Nanowire Networks. Angew. Chem., Int. Ed. 2004, 43, 6169-6173.

(13) Bartlett, P. N.; Gollas, B.; Guerin, S.; Marwan, J. The preparation and characterisation of H1-e palladium films with a regular hexagonal nanostructure formed by electrochemical deposition from lyotropic liquid crystalline phases. Phys. Chem. Chem. Phys. 2002, 4, 3835-3842.

(14) Whitehead, A. H.; Elliott, J. M.; Owen, J. R.; Attard, G. S. Electrodeposition of Mesoporous Tin Films. Chem. Commun. 1999, $331-332$.

(15) Wang, H.; Wang, L.; Sato, T.; Sakamoto, Y.; Tominaka, S.; Miyasaka, K.; Miyamoto, N.; Nemoto, Y.; Terasaki, O.; Yamauchi, Y. Synthesis of Mesoporous Pt Films with Tunable Pore Sizes from Aqueous Surfactant Solutions. Chem. Mater. 2012, 24, 1591-1598.

(16) Iqbal, M.; Li, C.; Wood, K.; Jiang, B.; Takei, T.; Dag, Ö.; Baba, D.; Nugraha, A. S.; Asahi, T.; Whitten, A. E.; Hossain, M. S. A.; Malgras, V.; Yamauchi, Y. Continuous Mesoporous Pd Films by Electrochemical Deposition in Nonionic Micellar Solution. Chem. Mater. 2017, 29, 6405-6413.

(17) Li, C.; Jiang, B.; Miyamoto, N.; Kim, J. H.; Malgras, V.; Yamauchi, Y. Surfactant-Directed Synthesis of Mesoporous Pd Films with Perpendicular Mesochannels as Efficient Electrocatalysts. J. Am. Chem. Soc. 2015, 137, 11558-11561.

(18) Li, C.; Dag, Ö.; Dao, T. D.; Nagao, T.; Sakamoto, Y.; Kimura, T.; Terasaki, O.; Yamauchi, Y. Electrochemical Synthesis of Mesoporous Gold Films Toward Mesospace-Stimulated Optical Properties. Nat. Commun. 2015, 6, 6608.

(19) Bianchini, C.; Shen, P. K. Palladium-Based Electrocatalysts for Alcohol Oxidation in Half Cells and in Direct Alcohol Fuel Cells. Chem. Rev. 2009, 109, 4183-4206.

(20) Ksar, F.; Ramos, L.; Keita, B.; Nadjo, L.; Beaunier, P.; Remita, H. Bimetallic Palladium-Gold Nanostructures: Application in Ethanol Oxidation. Chem. Mater. 2009, 21, 3677-3683.

(21) Chen, A.; Ostrom, C. Palladium-Based Nanomaterials: Synthesis and Electrochemical Applications. Chem. Rev. 2015, 115, 11999-12044.

(22) Antolini, E. Palladium in Fuel Cell Catalysis. Energy Environ. Sci. 2009, 2, 915-931.

(23) Yin, Z.; Lin, L. L.; Ma, D. Construction of Pd-based nanocatalysts for fuel cells: opportunities and challenges. Catal. Sci. Technol. 2014, 4, 4116-4128.

(24) Wang, A.-L.; He, X.-J.; Lu, X.-F.; Xu, H.; Tong, Y.-X.; Li, G.-R. Palladium-Cobalt Nanotube Arrays Supported on Carbon Fiber Cloth 
as High-Performance Flexible Electrocatalysts for Ethanol Oxidation. Angew. Chem., Int. Ed. 2015, 54, 3669-3673.

(25) Hammer, B.; Nørskov, J. K. Theoretical Surface Science and Catalysis-Calculations and Concepts. Adv. Catal. 2000, 45, 71-129.

(26) Padama, A. A. B.; Cristobal, A. P. S.; Ocon, J. D.; Diño, W. A.; Kasai, H. Effects of Adsorbates (CO, $\mathrm{COH}$, and $\mathrm{HCO}$ ) on the Arrangement of $\mathrm{Pd}$ Atoms in $\mathrm{PdCu}(111)$. J. Phys. Chem. C 2017, 121, 17818-17826.

(27) Jiang, K.; Wang, P.; Guo, S.; Zhang, X.; Shen, X.; Lu, G.; Su, D.; Huang, X. Ordered PdCu-Based Nanoparticles as Bifunctional Oxygen-Reduction and Ethanol-Oxidation Electrocatalysts. Angew. Chem., Int. Ed. 2016, 55, 9030-9035.

(28) Koganti, V. R.; Dunphy, D.; Gowrishankar, V.; McGehee, M. D.; Li, X.; Wang, J.; Rankin, S. E. Generalized Coating Route to Silica and Titania Films with Orthogonally Tilted Cylindrical Nanopore Arrays. Nano Lett. 2006, 6, 2567-2570.

(29) Koganti, V. R.; Rankin, S. E. Synthesis of Surfactant-Templated Silica Films with Orthogonally Aligned Hexagonal Mesophase. J. Phys. Chem. B 2005, 109, 3279-3283.

(30) Choi, K.-S.; McFarland, E. W.; Stucky, G. D. Electrocatalytic Properties of Thin Mesoporous Platinum Films Synthesized Utilizing Potential-Controlled Surfactant Assembly. Adv. Mater. 2003, 15, 2018-2021.

(31) Xu, C.; Zhang, Y.; Wang, L.; Xu, L.; Bian, X.; Ma, H.; Ding, Y. Nanotubular Mesoporous PdCu Bimetallic Electrocatalysts toward Oxygen Reduction Reaction. Chem. Mater. 2009, 21, 3110-3116.

(32) Denkova, A. G.; Mendes, E.; Coppens, M.-O. Kinetics and Mechanism of the Sphere-to-Rod Transition of Triblock Copolymer Micelles in Aqueous Solutions. J. Phys. Chem. B 2009, 113, 989-996.

(33) Luo, W.; Zhao, T.; Li, Y.; Wei, J.; Xu, P.; Li, X.; Wang, Y.; Zhang, W.; Elzatahry, A. A.; Alghamdi, A.; Deng, Y.; Wang, L.; Jiang, W.; Liu, Y.; Kong, B.; Zhao, D. A Micelle Fusion-Aggregation Assembly Approach to Mesoporous Carbon Materials with Rich Active Sites for Ultrasensitive Ammonia Sensing. J. Am. Chem. Soc. 2016, 138, 12586-12595.

(34) Liang, Z. X.; Zhao, T. S.; Xu, J. B.; Zhu, L. D. Mechanism Study of the Ethanol Oxidation Reaction on Palladium in Alkaline Media. Electrochim. Acta 2009, 54, 2203-2208.

(35) Noh, Y.; Kim, Y.; Lee, S.; Lim, E. J.; Kim, J. G.; Choi, S. M.; Seo, M. H.; Kim, W. B. Exploring the Effects of the Size of Reduced Graphene Oxide Nanosheets for Pt-Catalyzed Electrode Reactions. Nanoscale 2015, 7, 9438-9442.

(36) Tang, L.; Wang, Y.; Li, Y.; Feng, H.; Lu, J.; Li, J. Preparation, Structure, and Electrochemical Properties of Reduced Graphene Sheet Films. Adv. Funct. Mater. 2009, 19, 2782-2789.

(37) Dong, L.; Gari, R. R. S.; Li, Z.; Craig, M. M.; Hou, S. Graphene-supported platinum and platinum-ruthenium nanoparticles with high electrocatalytic activity for methanol and ethanol oxidation. Carbon 2010, 48, 781-787.

(38) Wen, D.; Herrmann, A.-K.; Borchardt, L.; Simon, F.; Liu, W.; Kaskel, S.; Eychmüller, A. Controlling the Growth of Palladium Aerogels with High-Performance toward Bioelectrocatalytic Oxidation of Glucose. J. Am. Chem. Soc. 2014, 136, 2727-2730.

(39) Franceschini, E. A.; Bruno, M. M.; Williams, F. J.; Viva, F. A.; Corti, H. R. High-Activity Mesoporous Pt/Ru Catalysts for Methanol Oxidation. ACS Appl. Mater. Interfaces 2013, 5, 10437-10444.

(40) You, H.; Zhang, F.; Liu, Z.; Fang, J. Free-Standing Pt-Au Hollow Nanourchins with Enhanced Activity and Stability for Catalytic Methanol Oxidation. ACS Catal. 2014, 4, 2829-2835.

(41) You, H.; Fang, J. Particle-Mediated Nucleation and Growth of Solution-Synthesized Metal Nanocrystals: A New Story Beyond the Lamer Curve. Nano Today 2016, 11, 145-167.

(42) Zhang, L.; Li, J.; You, H.; Ma, C.; Lan, S.; Wu, Z.; Zeng, J.; Tian, F.; Fang, J. In Situ Probing of the Particle-Mediated Mechanism of WO3 -Networked Structures Grown inside Confined Mesoporous Channels. Small 2017, 14, 1702565.

(43) Fang, J.; Zhang, L.; Li, J.; Lu, L.; Ma, C.; Cheng, S.; Li, Z.; Xiong, Q.; You, H. A General Soft-Enveloping Strategy in the
Templating Synthesis of Mesoporous Metal Nanostructures. Nat. Commun. 2018, 9, 521.

(44) Li, C.; Iqbal, M.; Lin, J.; Luo, X.; Jiang, B.; Malgras, V.; Wu, K. C.-W.; Kim, J.; Yamauchi, Y. Electrochemical Deposition: An Advanced Approach for Templated Synthesis of Nanoporous Metal Architectures. Acc. Chem. Res. 2018, 51, 1764-1773. 